
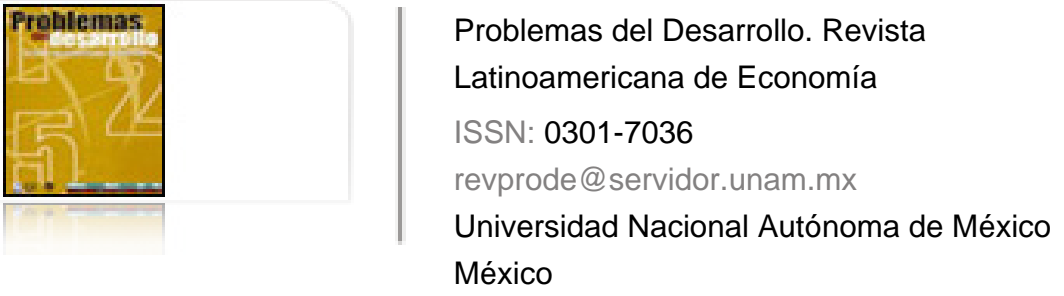

Rivera Ríos, Miguel Ángel; Robert, Verónica; Yoguel, Gabriel CAMBIO TECNOLÓGICO, COMPLEJIDAD E INSTITUCIONES: EL CASO DE ARGENTINA Y MÉXICO

Problemas del Desarrollo. Revista Latinoamericana de Economía, vol. 40, núm. 157, abril-junio, 2009, pp. 75-109

Universidad Nacional Autónoma de México

Distrito Federal, México

Disponible en: http://www.redalyc.org/articulo.oa?id=11820087005

Cómo citar el artículo

Número completo

- Más información del artículo

Página de la revista en redalyc.org

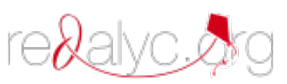

Sistema de Información Científica

Red de Revistas Científicas de América Latina, el Caribe, España y Portugal Proyecto académico sin fines de lucro, desarrollado bajo la iniciativa de acceso abierto 


\title{
CAMBIO TECNOLÓGICO, COMPLEJIDAD E INSTITUCIONES: EL CASO DE ARGENTINA Y MÉXICO
}

\author{
Miguel Ángel Rivera Ríos* \\ Verónica Robert** \\ Gabriel Yoguel***
}

Fecha de recepción: 3 de febrero de 2009. Fecha de aceptación: 4 de mayo de 2009.

\section{Resumen}

El artículo conjuga los aportes de varias teorías sobre el cambio tecnológico e institucional que ayudan a comprender la persistencia de la "trampa del atraso" en el sentido de fallas persistentes de coordinación para impulsar el aprendizaje tecnológico. Como punto de partida se asume un marco teórico evolucionista ampliado, cuyo eje es la diversidad de los agentes en términos de capacidades de absorción y conectividad y los efectos de retroalimentación en los procesos de aprendizaje que potencian procesos de apropiación, cambio estructural y destrucción creativa, dando lugar a dinámicas no lineales que imprimen su especificidad en los senderos de desarrollo. El tratamiento teórico se complementa con los resultados de dos trabajos empíricos llevados a cabo de manera independiente en industrias argentinas y mexicanas.

Palabras clave: América Latina, cambio tecnológico, sistemas complejos, desarrollo económico AsialAmérica Latina, desarrollo industrial y cambio estructural.

* Profesor de la Facultad de Economía, UNAM. Correo electrónico: mriver@servidor.unam.mx.

** Investigadora-docente del Instituto de Industria, de la Universidad Nacional de General Sarmiento, Argentina: Correo electrónico: vrobert@gmail.com.

*** Profesor titular e Investigador-docente del Instituto de Industria, de la Universidad Nacional de General Sarmiento, Argentina: Correo electrónico: gyoguel@ungs.edu.ar. 


\section{Abstract}

This article combines the contributions of a number of theories on technological and institutional change that help to explain the persistence of the "underdevelopment trap" in the sense of persistent flaws in coordination to drive technological learning. As its point of departure, it assumes a broadly evolutionist theoretical framework, whose axis is the diversity of agents in terms of capacities of absorption and connectivity and the effects of feedback in the learning processes that empower processes of appropriation, structural change and creative destruction, giving rise to non-linear dynamics that impose their specificity on development paths. The theoretical treatment is complemented by the results of two empirical studies carried out independently in Argentine and Mexican industries.

Key words: Latin America, technological change, complex systems, economic development in Asia/Latin America, industrial development and structural change.

\section{Résumé}

L'article conjugue les apports de plusieurs thérories sur le changement technologique et institutionnel qui aident à comprendre la persistance du "piège du retard", dans le sens où se perpétuent des failles dans la coordination pour impulser l'apprentissage technologique. Comme point de départ, il est adopté un cadre théorique évolutionniste amplifié, dont l'axe est la diversité des agents, en termes de capacités d'absorption et de connectivité, et les effets de rétroalimentation dans les processus d'apprentissage qui potencialisent les processus d'appropriation, de changement structurel et destruction créative, donnant lieu à des dynamiques non linéaires qui marquent les sentiers du développement de l'empreinte de leur spécificité. Le traitement théorique est complémenté par les résultats de deux travaux empiriques menés à bien indépendamment dans des industries argentines et mexicaines.

Mots clés: Amérique latine, changement technologique, systèmes complexes, développement économique Asie/Amérique latine, développement industriel et changement structurel.

\section{Resumo}

O artigo conjuga as aportações de várias teorias sobre a mudança tecnológica e institucional que ajudam a compreender a persistência da "armadilha do atraso" no sentido de falhas persistentes de coordenação para impulsionar o aprendizado tecnológico. Como ponto de partida asume-se um enquadramento teórico evolucionista ampliado, cujo eixo é a diversidade dos agentes em termos de capacidades de absorção e conectividade e os efeitos de retroalimentação nos processos de aprendizagem que potencializam processos de apropriação, mudança estrutural e destruição creativa, dando lugar a dinâmicas não lineares que imprimem sua especificidade aos sendeiros de desenvolvimento. $O$ tratamento teórico complementa-se com os resultados de dois trabajos empíricos levados a cabo de maneira independente em indústrias argentinas e mexicanas.

Palavras-chave: América Latina, mudança tecnológica, sistemas complexos, desenvolvimento econômico Ásia/América Latina, desenvolvimento industrial e mudança estrutural.

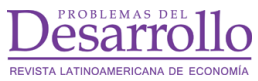

Vol. 40, núm. 157, abril-junio / 2009 


\section{Introducción}

n los pasados 30 años se ha producido un crecimiento casi explosivo de nuevas
formulaciones teóricas centradas en el estudio del cambio tecnológico y en la
relación que guarda éste con el crecimiento y el desarrollo económico. Los aportes más avanzados se encuentran en: $a$ ) la teoría microeconómica de la innovación (Nelson y Winter, 1982; Dosi, 1988, 2004; Dosi et al., 1993; Antonelli, 2001); b) la orientada al estudio de las revoluciones tecnológicas (Freeman y Pérez, 1988; Pérez, 2001), c) la teoría del aprendizaje organizacional (Shanon, 1993; March, 1996; Levinthal, 1996; Volberda, 1998), d) la teoría del conocimiento (Levinthal, 1996; March, 1996; Cowan, David y Foray 2001; Nooteboom, 2000; Johnson, Lorenz y Lundvall, 2001; Erbes et al., 2006) y e) la de los sistemas complejos, tanto en la vertiente evolucionista y neoschumpeteriana (Silverberg et al., 1988; Dosi y Kaniovski,

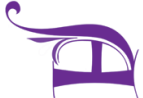
1994; Dosi y Nelson, 1994; Antonelli 2007, Metcalfe, 2007; Foster, 2005) como la que tiene su origen en el Instituto de Santa Fe (Arthur, Durlauf y Lane, 1997; Holland, 2004, Booker et al., 2005).

Al mismo tiempo se desarrollan otras líneas de estudio ligadas al cambio institucional (North, 1984, 1993, 2005 y North y Thomas, 1978), a los planteamientos que conceptualizan el desarrollo económico como cambio en el funcionamiento de la sociedad (Hoff y Stiglitz 2002, Hoff, 2002; Acemoglu, Johnson y Robinson, 2001; Banerjee, 1998) y los enfoques del desarrollo tardío de Amsden $(1989,2001)$ y Amsden y Chu (2003).

Estas diversas corrientes de la economía heterodoxa han renovado el interés en el estudio del desarrollo económico como un fenómeno que depende, desde una perspectiva no determinista, 1) del aprendizaje y la subsecuente acumulación de capacidades tecnológicas, 2) de la calidad de los procesos de destrucción creativa y apropiación, 3) del perfil de especialización productiva y el desarrollo de procesos de cambio estructural, y 4) del tipo de instituciones que gobiernan el funcionamiento de la sociedad y las conductas nuevas de los agentes. En relación con esas dimensiones es que el enfoque de complejidad aplicado a las ciencias sociales — por resaltar la idea de desequilibrio, irreversibilidad temporal y estructural como consecuencia de un path dependence no ergódico e incertidumbre radical - adquiere un papel clave para aproximar y abrir el diálogo entre las corrientes teóricas mencionadas.

En ese marco, este artículo tiene como uno sus objetivos centrales interrelacionar y hacer que dialoguen las corrientes arriba mencionadas. Este ejercicio de interrelación teórica, creemos, contribuirá a dar respuesta a la pregunta de por qué en algunos países las instituciones y la estructura productiva se configuran de manera que abren 
trayectorias de innovación o creatividad social en general (países desarrollados y los que llamaremos tardíos del tipo $A$ ) y en otros casos no (los que llamaremos tardíos del tipo $B)$.

Al tomar como fundamento la teoría del desarrollo tardío, llamamos países tipo $A$ a los que han sustentado su crecimiento en el aprendizaje colectivo y obtienen rentas económicas internacionales basadas en ese mismo mecanismo (apropiación basada en el aprendizaje). El desarrollo económico fundamentado en el aprendizaje implica una estructura organizativa e institucional, en la que sobresale una sistemática intervención estatal capaz de movilizar a la población a fin de lograr el cambio estructural y el elevamiento de la competitividad internacional, logros no sólo absolutos, sino también relativos por cuanto implica el cierre de la brecha internacional. Aunque existen diferencias nacionales (heterogeneidad nacional), son representativos de este grupo desde las economías dinámicas de Asia, incluyendo a China e India, hasta los países europeos meridionales, como Portugal, España y Grecia, que generaron procesos de catch-up en las últimas décadas. En contraposición, en los países tardíos del tipo $B$ el aprendizaje colectivo ha sido fallido, la intervención estatal ha estado desestructurada o actúa de manera depredadora, por lo cual subsiste históricamente una fuerte polarización social que ha generado una ampliación de la brecha internacional. El grupo emblemático es el de América Latina, pero en Asia cabe incluir a Filipinas e Indonesia. Como regla estas naciones obtienen rentas económicas internacionales basadas sobre todo en la renta del suelo, lo que da lugar a ciclos de prosperidad y desastre. Investigaciones recientes ponen de manifiesto que en la última década - en especial, en las economías asiáticas - se han verificado avances en capacidades de innovación que los hacen irreconocibles desde una óptica latinoamericana (véase Ernst, 2009).

La hipótesis, enmarcada en el reconocimiento de los procesos de innovación en América Latina, establece que las fallas en el cambio estructural radican en el funcionamiento de conjunto de la sociedad, lo que exige relacionar el sistema institucional con el productivo. Varios estudios de caso realizados en Argentina y México nos servirán para fundamentar empíricamente los rasgos de la organización productiva e institucional que diferencian a ambos países, así como los del resto de América Latina (tardíos del tipo $B$ ) de las economías dinámicas de Asia (tardíos del tipo $A$ ).

A la hora de tratar de ordenar y hacer dialogar estos aportes emergen diversos problemas metodológicos que especificaremos de manera sucinta. En relación con la unidad de análisis, como lo reconocen Coriat y Dosi (2002), el pensamiento evolucionista, al igual que la teoría del aprendizaje, toma un sesgo crecientemente microeconómico. En una nueva época histórica, caracterizada por la aceleración del 
cambio tecnológico, exige pensar de forma sistémica, trasladando la unidad de análisis en el ámbito de nación enmarcada explícitamente en procesos de escala mundial. Además del problema de la unidad de análisis, otra dificultad es la transposición de enfoques analíticos que han logrado una importante difusión mundial. El estudio del aprendizaje organizacional y los aportes de la teoría de la innovación se propagaron ampliamente entre académicos e intelectuales latinoamericanos y de otros países en desarrollo. Esta difusión de enfoques y tratamientos teóricos, aunque positiva, puede presentar ciertos problemas, en la medida en que la metodología del pensamiento teórico moderno convierta procesos históricos en objetos o modelos teóricos (Blaug 1992; Fogel, 1997; Stiglitz, 1992), que como tales puedan transponerse a países que siguen una trayectoria “tardía”. Por ejemplo, ¿cuál es el estatuto epistemológico para enfocar desde la perspectiva de los Sistemas Nacionales de Innovación las actividades de empresas, gobierno, universidades, etcétera, en países que, debido al patrón de especialización productiva predominante, muestran una baja dinámica innovadora?

La clave para resolver estos problemas de integración depende del carácter de los soportes analítico-metodológicos que se elijan y de la unicidad de los mismos. El funcionamiento del sistema productivo y socioinstitucional debe verse necesariamente desde la óptica de la complejidad social, es decir, aquélla donde existe intencionalidad en las acciones de los agentes (Antonelli, 2007) y donde la cultura brinda el contexto más amplio de interacción humana (Nooteboom, 2000). A su vez, no puede hacerse abstracción de que las actividades productivas - de las que fluyen las innovaciones - están enmarcadas y condicionadas por la estructuración del poder político. Este último tiene un papel determinante en la conformación institucional que gobierna la actividad innovadora o el aprendizaje. A su vez resulta indispensable - para alcanzar los objetivos que propone este artículo - interrelacionar la teoría del crecimiento con la teoría del desarrollo, que constituye el fundamento de la tipología que diferencia a las economías tardías de los tipos $A$ y $B .^{1}$

\footnotetext{
Como se desprende de los análisis de Marx (1946), Smith (2007), Schumpeter (1934) y Kuznets (1973), el crecimiento económico implica un aumento sostenido de la productividad, lo cual se puede lograr por varias vías; la primordial y duradera es la vía schumpeteriana (por medio de la innovación), pero la productividad puede aumentar también por el aumento del coeficiente de inversión o del aumento de la división del trabajo (véase Mokyr, 1990). Desde el punto de vista del desarrollo, el gran cambio histórico del siglo XX consiste en el cierre de la brecha internacional de países tardíos que carecían de capacidad de innovación, pero sí de aprendizaje con incrementos de la productividad que les permite extraer rentas económicas internacionales en industrias "intermedias" (sobre el aprendizaje véase Amsden, 1989 y Bell y Pavitt, 1992; sobre rentas internacionales véase Dabat et al., 2006).
} 
Para lograr esas metas de integración y fundamentación, el artículo se organiza de la siguiente forma: en la primera sección se expone la concepción evolucionista correspondiente a lo que Kuznets llama el crecimiento económico moderno, o sea aquel basado en la innovación en sentido schumpeteriano. Para ello hablaremos de un marco teórico evolucionista ampliado, tomando como eje la complejidad y las capacidades de absorción y conectividad de los agentes, con énfasis en los efectos feedback, para potenciar los procesos de apropiación, cambio estructural y destrucción creativa.

En seguida se exponen los resultados de dos trabajos empíricos llevados a cabo de manera independiente en industrias argentinas y mexicanas que muestran el limitado grado de complejidad de las redes o estructuras sectoriales. Después se exponen los aspectos de la teoría del cambio institucional de North, que ayuda a comprender la persistencia de la "trampa del atraso" en el sentido de prolongación en el tiempo de condiciones originarias adversas y fallas recurrentes de coordinación para impulsar el aprendizaje tecnológico. Finalmente, se hace una propuesta de unificación del enfoque "tecnológico" con el institucionalista y se propone una agenda tentativa de investigación, enmarcada en una nueva teoría del desarrollo (Hoff y Stiglitz, 2002) que sigue la orientación establecida por North, pero incorpora las herramientas conceptuales y metodológicas propuestas por el enfoque de los sistemas complejos, en la línea de Metcalfe, Dosi y Antonelli.

\section{Marco teórico evolucionista ampliado: capacidad de absorción y conectividad en un sistema complejo}

En este primer apartado se presentan los conceptos claves del marco teórico que combina evolucionismo con sistemas complejos, con el fin de proponer un modelo que interprete el funcionamiento de un sistema económico, cuya dinámica dependa de la innovación. El enfoque de la complejidad permite proyectar el sistema económico en varios niveles ontológicos: firmas, redes de firmas, regiones o países, enfocados siempre desde la misma perspectiva dinámica. Así, se considera que el sistema cambia de acuerdo con dos propiedades fundamentales, la de autoorganización y la de adaptación y el grado de desarrollo de las capacidades de absorción y conectividad, de las que emergen los procesos de innovación, destrucción creativa, apropiabilidad y cambio estructural. La dinámica guiada por la autoorganización obedece a transformaciones en el sistema, resultado de sus propias reglas y rutinas, es decir, es el cambio condicionado por la trayectoria adquirida (dependencia del sendero o path 
dependence), siempre bajo el supuesto de conductas intencionales de los agentes. En este sentido, la dinámica impresa por la autoorganización obedece a cambios derivados de incentivos internos al sistema. Por otra parte, la propiedad de adaptación da cuenta de la habilidad del sistema, representado por agentes heterogéneos con diferente capacidad creativa (Antonelli, 2008) para realizar reconfiguraciones frecuentes que respondan a los cambios generados en el ambiente. De esta manera, esta propiedad produce cambios en el sistema que son respuesta a incentivos externos. No obstante, el sistema experimenta ajustes continuos no deterministas porque las expectativas de los agentes y las condiciones objetivas de la estructura económica y social muy frecuentemente no son coincidentes (Antonelli, 2008).

Las capacidades del sistema complejo se refieren a las competencias de los agentes en términos de absorción y conectividad que apuntan a la generación y circulación de conocimiento nuevo. La capacidad de absorción del sistema puede ser considerada como "la habilidad para reconocer nueva información externa, asimilarla y aplicarla" (Cohen y Levinthal, 1989). Esta capacidad no está relacionada únicamente con la posibilidad de tener acceso al conocimiento existente en el ambiente, sino que también implica la habilidad de identificar el conocimiento útil y de generar otro nuevo. En este sentido, esa capacidad puede ser equiparada a la noción de construcción de rutinas (Nelson y Winter, 1982), de capacidades dinámicas (Teece y Pisano, 1994) y de competencias endógenas (Roitter et al., 2008). Por su parte, la capacidad de conectividad está asociada al potencial con el que cuenta el sistema para establecer relaciones y generar interacciones con otros sistemas para incrementar su base de conocimiento. La capacidad de conectividad excede a la interacción simple e involucra interacciones seleccionadas, así como a la prioridad de relaciones que se establecen con otros sistemas en función de lo que éstos pueden brindar.

Desde la perspectiva de los procesos - influidos por las mencionadas capacidades - destacan los de destrucción creativa, cambio estructural y apropiación. El proceso de destrucción creativa hace referencia a la generación de microdiversidad y a la emergencia de mecanismos de selección, ya sea el mercado u otra institución; lo relevante es que la selección, en un sistema ya orientado en una trayectoria schumpeteriana, tenderá a premiar las conductas innovadoras de los agentes. Se considera que el sistema desarrolla procesos de cambio estructural si evoluciona en la dirección de reasignar - tanto desde una perspectiva estática como dinámica - sus recursos productivos. Ello requiere aumentar los esfuerzos de innovación y a la par disminuir el grado de heterogeneidad, así como incrementar la complementariedad de sus componentes (Ocampo, 2006). Por último, si el sistema tiene capacidad de captar de las 
rentas derivadas de la innovación porque desarrolla regímenes de apropiablidad que lo habilitan y porque logra colocarse en los segmentos más dinámicos de la cadena, entonces decimos que el sistema genera procesos de apropiación, si se supone por supuesto la renovación del ciclo tecnológico.

En este sentido, las propiedades de autoorganización y adaptación son las que conducen la dinámica global del sistema mediante el desarrollo de procesos de cambio estructural, apropiación y destrucción creativa que vuelven a un sistema económico y a sus instituciones y organizaciones proclives a la innovación. Con el proceso de destrucción creativa el sistema elimina las capacidades obsoletas y las reemplaza por capacidades nuevas, o da lugar al establecimiento de un diseño dominante y descarta otros. Con Metcalfe, Foster y Ramlogan (2006) asumimos que estos procesos conducen la dinámica de autotransformación del capitalismo, basada en dos pilares fundamentales. Por un lado, el componente creativo - sustentado en la actividad de innovación que se lleva adelante en el ámbito de la firma - es el responsable de la generación de microdiversidad. Por otro, el componente destructivo, que implica la reducción de esa microdiversidad: la selección. Este proceso está profundamente permeado por la especialización productiva y la matriz institucional predominante. Si la matriz institucional es adversa a la innovación, el proceso de destrucción creativa funciona deficientemente, lo que genera concentración económica y de poder no relacionada con la conducta innovadora. Por el contrario, en una matriz institucional innovadora, las rentas económicas que obtienen los agentes en el mercado están positivamente asociadas a la intensidad y calidad del proceso innovador. El cambio, en el ciclo de vida tecnológico determinará que las rentas se asocien después a la oligopolización de la producción.

Por otra parte, un sistema económico con la habilidad de transformar en riqueza al conocimiento generado puede desarrollarse sobre la base de un crecimiento retroalimentado. Este proceso está relacionado con la estructura de derechos de propiedad definida en la matriz institucional (véase el apartado "El desarrollo económico como cambio en el funcionamiento de la sociedad. Poder político, derechos de propiedad y matriz institucional"del presente artículo), pero también depende de las habilidades que tienen las firmas para definir estrategias de apropiación compatibles con los derechos de propiedad intelectual determinados en el marco jurídico. Por otro lado, a pesar de que la literatura define por lo general el proceso de apropiación en el ámbito de la firma y como un fenómeno circunscrito a la esfera microeconómica (Schumpeter, 1947; Arrow, 1962/2002; Teece, 1986), las transformaciones en los planos organizacionales e institucionales inscritas en el nuevo paradigma tecnológico 
obligan a considerar los planos meso y macroeconómicos de la apropiabilidad. La emergencia de tramas productivas, los desarrollos tecnológicos colaborativos, la aparición de clubes de innovación (Antonelli, 1999) y la creciente importancia del plano territorial de la competitividad en la descripción de los procesos de innovación ponen de manifiesto los determinantes mesoeconómicos de la apropiabilidad. Por otra parte, la forma colusiva ${ }^{2}$ o clásica de difusión de los beneficios del progreso tecnológico (Reinert, 1995), vinculada con el perfil de especialización productivo y comercial, da cuenta de las dimensiones macroeconómicas de la apropiación.

De esta manera, la dimensión macro de la apropiabilidad está en estrecha conexión con el desarrollo de procesos de cambio estructural. Dichos procesos implican la generación de cambios en los patrones de inserción externa, orientándolos hacia productos diferenciados con rendimientos crecientes a escala y una mayor elasticidad de ingreso (Reinert, 2007). Por tanto, un giro en la especialización productiva en esta dirección implicaría seguir en un sendero de crecimiento retroalimentado: mayores posibilidades de aprendizaje e innovación, mayor productividad, ampliación del mercado y mejoras en la asignación de recursos (Dosi, Pavitt y Soete 1990). No obstante, el desarrollo de este tipo de proceso está condicionado por la estructura de poder, las características de su élite (Cimoli y Rovira, 2008) y la subconsecuente determinación de la matriz institucional.

La acción de la matriz institucional no está sujeta a relaciones lineales de causaefecto, sino a relaciones complejas donde la indeterminación, el desequilibrio y la retroalimentación son las fuerzas relevantes. Es posible pensar el cambio institucional como una propiedad emergente del sistema que se gesta a partir de la interacción de los agentes económicos en sus múltiples planos, con especial énfasis en las capacidades de absorción y conectividad desarrolladas por éstos (Erbes, Robert y Yoguel, 2008).

El modelo evolucionista estándar propone la imagen teórica de una población de firmas que compiten por la solución que más contribuya al progreso económico. El mecanismo seleccionador, una combinación entre elementos mercantiles e institucionales, posibilita la innovación empresarial: la apropiación de rentas económicas y el progreso económico. Sin embargo, esta formulación básica deja abiertas diversas interrogantes ya discutidas en la literatura reciente. La más conocida es la incompa-

2 Mientras la primera describe un proceso de reducción de costos y precios en el marco de rendimientos marginales decrecientes, la segunda alude a procesos de innovación asociados a generación de variedad y aumento de rentas económicas acompañados de incrementos salariales factibles bajo la forma de competencia imperfecta y rendimientos crecientes. 
Figura 1

Complejidad en un sistema económico

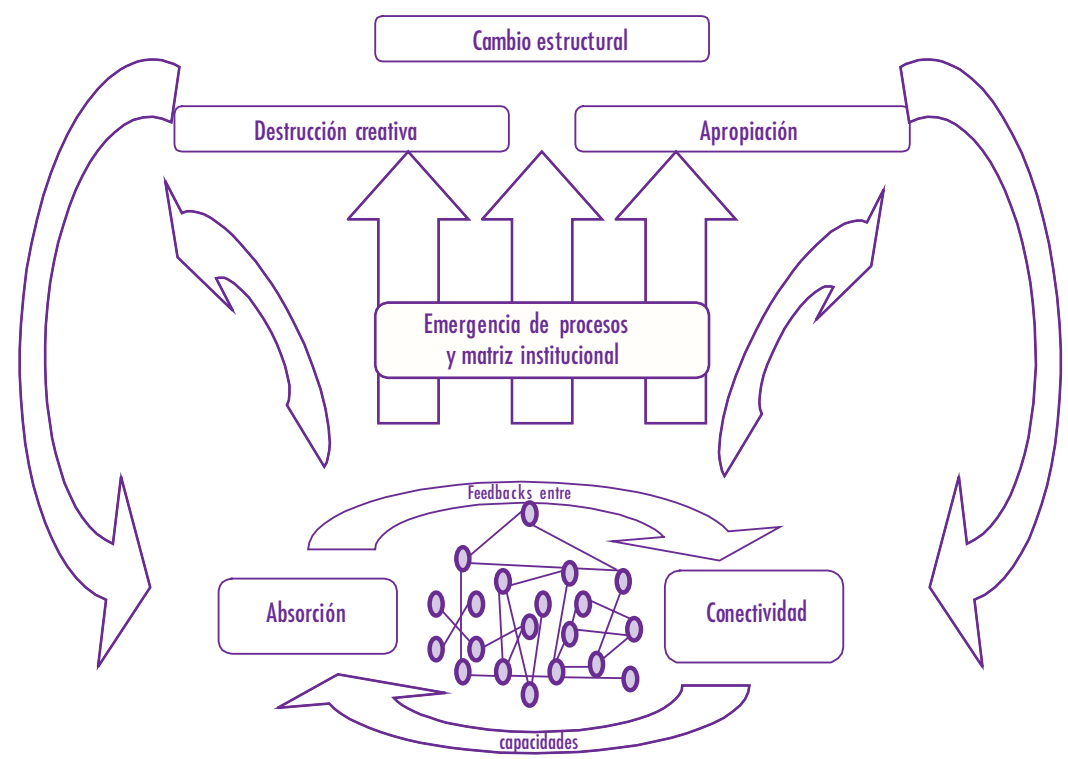

Fuente: Elaboración propia basado en Lewin, 1992.

tibilidad entre rutinas e innovación radical, lo que exige tomar de la teoría del aprendizaje organizacional su propuesta de ciclos cognoscitivos.

Ahora debemos hacernos la pregunta de si el enfoque evolucionista ampliado a partir de la teoría de los sistemas complejos es relevante para un país en desarrollo, sobre todo del tipo $B$. Ciertamente lo es porque expresa las metas del progreso y del crecimiento económico moderno. Por definición, en un país en desarrollo del tipo $B$ los rasgos estructurales predominantes son los reducidos niveles en las capacidades y procesos mencionados. En particular, las bajas capacidades de absorción y conectividad derivan del patrón de especialización adoptado y de la limitada complementariedad entre los agentes, quienes actúan en una estructura institucional que limita el crecimiento con retroalimentación. A su vez, los feedback o procesos de retroalimentación en los países en desarrollo se manifiestan en una persistencia de la heterogeneidad estructural que limitan o imposibilitan el desarrollo de procesos de cambio estructural. La pregunta relevante, dado el planteamiento anterior, es por qué en los países tardíos del tipo $B$ hay diversos impedimentos a un mayor grado de complejidad. La respuesta a la pregunta anterior exige tomar en cuenta también los factores político-institucionales, lo que haremos en los apartados "El desarrollo eco- 
nómico como cambio en el funcionamiento de la sociedad. Poder político, derechos de propiedad y matriz institucional" y "Cambio institucional y capacidad de innovación: una referencia comparativa al caso de América Latina”, del presente artículo.

Con apoyo de este marco teórico examinaremos a continuación las actividades de empresas argentinas y mexicanas en algunos sectores industriales para definir el alcance de sus actividades de aprendizaje e innovación y de sus capacidades de absorción y conectividad.

\section{Las fallas en el aprendizaje tecnológico en empresas argentinas y mexicanas}

América Latina experimentó una sucesión de choques social y económicamente traumáticos a partir de fines de la década de los setenta, en el contexto de cambios de lo que Carlota Pérez conceptualiza como paradigma tecnoeconómico y sistema socioinstitucional (Pérez, 2001 y 2004). Los cambios tecnológicos convirtieron las estrategias de desarrollo en un "blanco móvill", cuyas exigencias no fueran captadas e interpretadas por las élites dirigentes. Los resultados mayormente adversos son los que expondremos a continuación.

La reforma neoliberal en el contexto de crisis generalizada produjo un conjunto de repercusiones sociales que definieron el curso del cambio estructural de las siguientes dos décadas. Por su capacidad de ruptura de las tendencias preexistentes podemos definir esa reforma como un choque exogéno-endógeno. El agotamiento de la industrialización sustitutiva en el contexto de apertura comercial y financiera se tradujo en una gran mortandad fundamentalmente de pequeñas y medianas firmas, acompañada por el surgimiento de nuevos agentes de mayor tamaño, asociados en algunos casos al acceso al crédito internacional. Estas transformaciones fueron la base de un nuevo patrón de especialización productiva basado esencialmente en commodities industriales y de origen agropecuario, así como en actividades intensivas en recursos naturales, donde predominó una mayor concentración económica. Un efecto auténticamente regresivo en general fue en una primera fase el abandono de ramas de ingeniería, el despido masivo de trabajadores, la intensificación de los procesos de outsourcing y de subcontratación, así como el elevamiento tanto absoluto como relativo de las importaciones ${ }^{3}$ (Benavente et al., op. cit.; Timol y Correa, 2005; Reinert,

3 Esa precisión alcista de las importaciones (en el caso de partes y componentes) se explica por el perfil de especializacion y ruptura de encadenamientos, en tanto que la de bienes suntuarios por la concentración del ingreso en favor del decil más opulento. 
2007); y, en una segunda fase, el deterioro de las capacidades tecnológicas de esos trabajadores y de las generaciones subsiguientes.

El más importante de esos choques fue la apertura comercial acelerada de fines de los años setenta en Argentina, desde el enfoque monetario de la balanza de pagos, y durante los ochenta y noventa en ambos países, cuya pretensión, con las reformas neoliberales, era hacer más eficientes a las empresas y por ende a las economías. También tuvieron un fuerte impacto la liberalización financiera (que en Argentina tuvo su mayor impulso durante la última dictadura militar) y la creciente participación de empresas extranjeras con tratamiento no discriminatorio en relación con el capital de origen nacional. En conjunto, ese proceso fue fallido y muchas empresas perecieron antes de modificar su trayectoria, y el núcleo endógeno se vio debilitado (en el sentido de Fajnzylber, 1983). En ese marco, las fuertes diferencias entre las perspectivas de los agentes y las condiciones objetivas de funcionamiento (Antonelli, 2008) provocadas por la apertura acelerada y la liberación financiera desalentaron a los agentes que juegan contra las reglas (que persisten en el aprendizaje pese a las condiciones desfavorables). Los atributos de acumulatividad (el comportamiento de la empresa está guiado por su path dependence o también la estructura arquitectónica de la matriz institucional) explican el débil aprendizaje tecnológico en el nuevo contexto de apertura y reinserción global.

Como lo explican Reinhardt y Wilson Peres (2000) y otros autores (Benavente et al., 1996; Yoguel et al, 2008), Argentina y México, dentro de una herencia común propia de la trayectoria de la industrialización por sustitución de importaciones (ISI), se integran al "nuevo modelo económico" con ciertas diferencias. En ambos destaca el peso de las industrias especializadas en commodities industriales, dominada por grandes empresas nacionales y transnacionales que pasan de la fase ISI a la post-ISI. Igualmente en ambos países la sucesión de choques endógeno-exógenos tiene una faceta negativa que implica la destrucción parcial del tejido social y productivo (con regeneraciones posteriores) y se desintegran en un grado significativo las estructuras institucionales, tendiendo a sobrevivir las instituciones inferiores, en tanto que las superiores $^{4}$ tienden a quedar incompletas" (Hoff y Stiglitz, 2002). Es significativo en ambos países que las filiales de las empresas transnacionales dominen, como lo habían hecho antes, los sectores de tecnología media-alta o alta, donde los esfuerzos

$4 \quad$ Hoff y Stiglitz entienden por instituciones inferiores aquellas que perpetúan el atraso económico (la aparcería, por ejemplo), en tanto que las superiores son las que apoyan el aprendizaje y, en general, la incorporación de la población al proceso de desarrollo, incluyendo las instituciones políticas que posibilitan el control social o ciudadano de las actividades gubernamentales (op. cit., pp. 395 y 419). 
de innovación son básicamente incorporados, lo que limita los spill-overs al resto del sistema productivo. Esto último, o sea el desplazamiento de la empresa nacional por la extranjera en los sectores más dinámicos y por ende más lucrativos, principalmente el automotor — no sólo terminales sino también proveedores de ensambles y subensambles - , ha sido conceptualizado por Amsden como crowding out (2001). La citada autora (op. cit., pp. 207 y ss) destaca esa diferencia al hablar de los emuladores de Japón (Corea del sur y Taiwán, en primer lugar) y los emuladores de Estados Unidos (los países latinoamericanos). Las implicaciones son decisivas para el aprendizaje, pues en los países tardíos del tipo $A$, el agente empresarial nacional actuará, ceteris paribus, cohesionando el aprendizaje a partir del desarrollo de capacidades de absorción y conectividad. Ello sucede débilmente en las empresas de los países tardíos del tipo $B$.

En el caso mexicano hay una diferencia marcada por su ubicación geográfica (Reinhardt y Peres, 2000). México se inserta a cadenas globales de producción por medio de un sui generis vehículo organizativo, que no es una empresa doméstica, pero tiene ciertos rasgos de territorialidad: la "maquiladora de exportación"; a la par que ésta florece, México sufre una pérdida de industria doméstica (electrónica, metalmecánica, textil-confección, etcétera), en tanto que los gigantes nacionales especializados en commodities industriales se involucran de manera muy limitada en las redes de proveedores de las firmas maquiladoras, aunque se expande en lo externo gracias a un tipo de cambio sobrevaluado (Dabat y Ordóñez, 2008). Ese tipo de cambio sobrevaluado facilita su expansión, vía inversiones a espacios económicos vecinos. La misma estructura productiva de estos países junto con los procesos de liberalización financiera son los que provocan una tendencia a la revaluación continua del tipo de cambio, que se traduce en lo que fue descrito en la bibliografía como perteneciente a la sintomatología de la enfermedad holandesa (Corden y Neary, 1982).

Al formar parte del Mercado Común del Sur (MERCOSUR), Argentina continúa en cierto modo un proceso de sustitución de importaciones modificado y ampliado (con cierta atenuación de la competencia global dentro del marco de regionalismo abierto). El predominio de las commodities industriales es más fuerte, a la vez que la dotación natural de recursos es determinante para sostener a industrias como maquinaria agrícola. La desindustrialización provocada por el régimen de convertibilidad desató una mortandad de firmas y de sectores comparativamente mayor, y el pasaje, al igual que en México, a una economía cuya dinámica dependía fuertemente de insumos, partes y subensambles y de productos finales importados. La devaluación constituyó una suerte de choque exógeno que devolvió a la industria a una trayectoria de aprendizaje aún vacilante o insegura, lo que demuestra la importancia pero 
también la insuficiencia de la política cambiaria para el desarrollo industrial. En este caso, la devaluación es necesaria para superar la enfermedad holandesa ${ }^{5}$ pero en muchos casos no se brinda el tiempo de maduración necesario para generar un aumento de las competencias de los agentes de menor productividad. La insuficiencia de las políticas industriales y tecnológicas agudiza ese problema. En consecuencia, la enfermedad holandesa ha vuelto a aparecer y los reclamos de una nueva devaluación se hicieron nuevamente presentes. En este proceso recurrente las limitadas capacidades de absorción y conectividad de los agentes, pero también la debilidad de los procesos de destrucción creativa, cambio estructural y apropiabilidad, se hicieron notorias.

En un estudio de Yoguel, Robert, Milesi y Erbes (2008) se ilustra empíricamente la limitada acumulación de capacidades tecnológicas entre una muestra de empresas industriales en Argentina. ${ }^{6}$ El estudio desarrolla una metodología de estimación de las capacidades de absorción y conectividad de los agentes aplicada al conjunto de tramas productivas estudiadas (véase nota 5). En el caso de la capacidad de absorción o competencias endógenas se analizan variables tales como la gestión de calidad, la organización del trabajo, la capacitación y la presencia de equipo de investigación y desarollo (I\&D). En el caso de la capacidad de conectividad se analizan las vinculaciones que establecen las firmas con diferentes tipos de agentes (otras empresas, cámaras empresariales y consultores y universidades y centros tecnológicos) y sus objetivos (comerciales, de cooperación tecnológica, capacitación, certificación de calidad, etcétera).

En un marco de fuerte heterogeneidad sectorial, las capacidades de absorción y conectividad son en promedio reducidas. A pesar del predominio de bajas competencias endógenas, el trabajo muestra que pueden señalarse algunas diferencias claves entre las tramas productivas según la importancia que adquieren cada una de las dimensiones que definen la capacidad de absorción. En primer lugar, sobresale la gestión de la calidad como un determinante fundamental de las competencias de las firmas pertenecientes al complejo automotor. Por el contrario, la organización del trabajo constituye una dimensión escasamente desarrollada en la totalidad de las tramas, lo que es un indicador de las limitaciones de los procesos de aprendizaje en las firmas. Desde la perspectiva de la conectividad de los agentes, destaca una reducida calidad de las vinculaciones. Los bajos niveles de conectividad con universidades y centros

5 En especial, la aplicación de un régimen de tipo de cambio múltiple.

6 El estudio de campo efectuado entre 2006 y 2008 abarcó a 408 empresas pertenecientes a seis tramas o redes definidas sectorialmente en las industrias: a) automotriz, b) siderurgia, c) maquinaria agrícola, d) confección con diseño, e) servicios petroleros y f) embarcaciones, y el sector industrial en el partido de Morón como grupo control. 
tecnológicos, así como el predominio de vinculaciones con objetivos comerciales, se conjugan con la situación observada de bajas competencias endógenas.

El hallazgo más relevante del estudio está en señalar la presencia de efectos feedbacks entre competencias y vinculaciones. Los modelos econométricos estimados permiten afirmar que la calidad de las vinculaciones depende positivamente de la capacidad de absorción de las firmas, cuando se controla por el tamaño, la propiedad del capital y la trama de pertenencia, lo que se observa casi de manera exclusiva entre empresas de capital extranjero (Erbes, Robert y Yoguel, 2008). Ello es relevante, en especial en las relaciones que las firmas entablan con universidades e instituciones de ciencia y tecnología e instituciones comerciales. Por el contrario, las vinculaciones (no mercantiles) que las firmas entablan entre sí no están asociadas a las competencias que poseen, lo que es consecuencia de la fuerte debilidad de la mayor parte de las tramas productivas estudiadas. Cabe resaltar que los esfuerzos de innovación en los últimos tres años siguen más bien la modalidad de incorporación de maquinaria, para dar lugar primordialmente a un tipo incremental de innovación de proceso (Yoguel et al., 2008). Todo ello implica que aunque con un contexto macroeconómico favorable que le ha permitido a Argentina crecer a tasas significativas desde el fin de la convertibilidad, las capacidades tecnológicas del país no parecen haberse desplegado. Ello lo entendemos como un efecto de la matriz institucional adversa a la innovación, que deriva en una dinámica regresiva entre las capacidades de absorción y vinculación.

En el caso de México, la "nueva" industria maquiladora de exportación, protagonista del auge exportador de los años noventa, atrajo un extraordinario interés de investigadores principalmente nacionales (Lara y Barajas, 2007; Contreras 2008; Carrillo y Hualde, 1997; Arias y Dutrenit, 2007), pero también del extranjero (Bair y Gereffi, 2003). Se efectuaron amplios estudios de caso en las aglomeraciones territoriales, alrededor o dentro de varias ciudades del norte del país, como Tijuana-Mexicali (audio-video), Sonora, Ciudad Juárez-Chihuahua (autopartes), Guadalajara (electrónica) y Torreón (confección de jeans de "paquete completo"). La mayoría de estos estudios no distinguía metodológica y analíticamente entre empresas nacionales y extranjeras, y se tomaba como unidad de estudio a la empresa "maquiladora de exportación". La colección de estudios de campo que tomamos aquí como base la efectuamos entre 2005 y 2008, y enfocaban a las empresas doméstico-locales integradas a las cadenas globales de producción (Dabat, Ordóñez y Rivera, 2005; Rivera, 2004, 2007). ${ }^{7}$

7 En los años que se mencionan se encuestaron a unas 100 empresas y organizaciones no empresariales (cámaras empresariales, agencias gubernamentales, centros de capacitación laboral y profesional, laboratorios de investigación). 
En el llamado cluster electrónico de Guadalajara (véase Dussel, 1994; Palacios, 2003) las empresas doméstico-locales se integraron a las redes de proveedores en manufactura global, como es el caso de equipo de cómputo, de telecomunicaciones y componentes electrónicos. Con el concepto de sistemas de conocimiento contra sistemas de producción (Bell y Albu, 1999) definimos un conjunto de indicadores (proporción de ingenieros y técnicos en la fuerza laboral, mejoras de productos y procesos, calidad de las vinculaciones) para estimar el aprendizaje tecnológico en el ámbito empresarial y se equiparaba con el concepto de upgrading (Gereffi,1995). ${ }^{8}$ Ello nos permitió visualizar la red de proveedores centralizados por la empresa líder o su filial como fuente de conocimiento tecnológico. Por ende, el ascenso en las cadenas de proveedores o upgrading abre la posibilidad de cambios en la organización de la firma y la generación de flujos de conocimiento (definidos como efectos de conectividad y absorción).

El resultado de la investigación puso de manifiesto el referido crowding-out, es decir, el confinamiento de las empresas locales a los productos de menor valor agregado. Pero al igual que en las tramas estudiadas por Yoguel et al. (2008) y de la taxonomía propuesta por Erbes et al. (2006), se encontraron "islotes" de innovación (caso del software embebido en Guadalajara). Desafortunadamente, en autopartes el número de firmas nacionales ha disminuido de manera continua y varias empresas de "maquinados" (partes automotrices) se han vuelto exportadoras independientes y se han orientado al mercado interno (véase también Lara y Barajas, 2007). La competencia china ha tenido un efecto devastador en confección y electrónica y desde la crisis de 2001 la industria ha cedido terreno en una diversidad de categorías de producto, sobre todo los de alto volumen y relativamente baja diferenciación, perdiendo al mismo tiempo los primeros lugares que tuvo en Estados Unidos (Dabat et al., 2005).

Para comprender lo que ha pasado en las industrias de ambos países como en América Latina en su conjunto, los enfoques tecnológicos en nuestra opinión no ofrecen una explicación adecuada como tiende a reconocer Katz (2008) y más recientemente Cimolli y Rovira (2008), entre otros. Sea que se estudie el fenómeno normativamente (como debe ser el mundo en lugar de cómo es), de manera descriptiva o de forma positivista, se tiende a mantener el nivel descriptivo más que analítico. Lo que queda claro del examen anterior es que las empresas no aprenden lo suficiente porque no están presentes los incentivos para hacerlo o porque dado el perfil de especialización no necesitan aprender más allá de cierto umbral, y cuando existen los incentivos organizacionales, las firmas domésticas chocan contra una serie de obs-

8 La metodología del trabajo de campo se explica en Dabat et al., 2005. 
táculos exógenos a las mismas. Como diría North, la matriz institucional es adversa a la innovación, limitando el grado de complejidad del sistema, lo que se manifiesta en débiles capacidades de absorción y conectividad y muy limitados procesos de retroalimentación.

Como se explicará más adelante, el cambio institucional y el correlativo aumento de complejidad requiere conmociones del sistema en su conjunto, pero de una intensidad y duración determinante como para inducir cambios institucionales y conductuales.

\section{El desarrollo económico como cambio en el funcionamiento de la sociedad. Poder político, derechos de propiedad y matriz institucional}

La obra de North, al plantear que el cambio tecnológico o la acumulación de capital no debe ser el punto de partida de la investigación, sino el punto de llegada, ha abierto una nueva perspectiva en el estudio del cambio socioeconómico. Lo que debemos explicar, dice North, es por qué unas sociedades (las pertenecientes al Mundo Occidental $^{9}$ ) han alcanzado un alto grado de prosperidad y otras (que representan la mayoría de la humanidad) no han escapado de la pobreza, la desigualdad extrema y el estancamiento (North y Thomas, 1978). La clave del crecimiento, como lo ponen de manifiesto las economías "occidentales", radica en una organización económica conductiva a la innovación, ${ }^{10}$ o sea, una matriz o marco institucional, un perfil de especialización y una estructura de derechos de propiedad capaces de canalizar los esfuerzos individuales hacia actividades que supongan una aproximación de la tasa privada de beneficio a la tasa social de beneficio (Ibid.). ${ }^{11}$ De acuerdo con North, la capacidad de innovación de una sociedad está repartida entre las organizaciones y

9 North y Thomas definen al mundo occidental como el grupo de países que la generalidad de los autores llama ricos o desarrollados.

10 En lugar del binomio conceptual neoclásico de eficiencia/ineficiencia usado por North al referirse a las instituciones, preferimos el concepto pro-innovativas, o en el caso opuesto, adversas a la innovación, porque aquel binomio conceptual remite al modelo de equilibrio general walrasiano, que formalmente se expresa como un modelo básico de la mecánica clásica, cuya utilidad analítica es puramente abstracta. Este modelo conduce a un equilibrio que se alcanza mediante predeterminaciones con independencia de las condiciones iniciales y garantiza la eficiencia paretiana. Cuando North centra el cambio institucional en el logro de "eficiencia" arrastra la herencia neoclásica de la que se despoja gradualmente, pero sólo la completa en su libro de 2005, donde declara: "la teoría neoclásica no fue creada para explicar el cambio económico" (p. vii).

11 En esa dirección, cabe aclarar que no cualquier estructura de derechos de propiedad promueve el desarrollo de una matriz institucional proclive a la innovación. Características como el espacio que deben tener los comunes (ya sea conocimiento científico o educación y salud), los derechos de propiedad intelectual y la política impositiva y tarifaria (derechos de exportación, régimen impositivo) son claves en los países que intentan hacer catching up. 
las instituciones, unificadas por los derechos de propiedad, que expresan la acción del poder sobre el funcionamiento de la sociedad. En ese contexto, Reinert (2007) plantea que el perfil de especialización productivo elegido se convierte en una variable condicionante del desarrollo y del crecimiento económico. Por tanto, existe una relación entre el modo en que un país se inserta en la economía mundial y la matriz institucional nacional.

Desde esta perspectiva, la pregunta crucial es ¿por qué las instituciones "conductivas a la innovación" no se han propagado al resto del mundo como de hecho esperaban los autores clásicos? La respuesta requiere un tratamiento teórico que explique cuáles son las consecuencias de la estructuración del poder político en las sociedades en general, para de allí pasar a las reglas que el Estado le impone a la sociedad para reglamentar la producción y apropiación de riqueza; esa reglamentación constituye su armazón institucional. La parte fundamental de esas reglas, o sea, los derechos de propiedad, definen lo que esa misma sociedad, si la consideramos en sí misma, es capaz de alcanzar en materia de crecimiento o desarrollo. Por encima de la economía nacional está la mundial, que posee su propia matriz institucional y estructura de poder, que debiera ser la unidad más amplia de análisis: obviamente las limitaciones de nuestro tratamiento nos impiden adoptar esa perspectiva que ha sido abordada, entre otros autores, por Pérez (2001 y 2004).

North afirma que la existencia misma del Estado como solución a las necesidades de las organizaciones humanas complejas pone de manifiesto una paradoja. El Estado es la fuente del progreso humano, pero a la vez es la esencia misma de los conflictos que explican la declinación o estancamiento de muchas sociedades (1984, p. 20). Ello se explica porque con una combinación de un cuerpo no escrito de códigos de conducta y de complejas formulaciones constitucionales acopla los derechos de propiedad para elevar las rentas económicas que van a manos del grupo que controla el Estado. En el marco de ese objetivo y subordinado al mismo, los grupos en el poder buscarán reducir los costos de transacción para aumentar el producto social y así elevar la parte que le regresa por tributación (Ibid).

North insiste en que esos dos objetivos están en tensión. El segundo objetivo abre la posibilidad de definir derechos de propiedad que apunten al aumento del producto social, en tanto que el primero está concebido para elevar el ingreso de los que detentan el poder y por ello cabe en la definición normativa de no conductivas a la innovación. Esta dicotomía está en la raíz del fracaso que experimentan la mayoría de las sociedades al tratar de lograr el crecimiento sostenido (op. cit., p. 25).

Aunque la constitución del poder, de acuerdo con North, implica anteponer una estructura de derechos de propiedad no conductivos a la innovación y ésa puede 
prolongarse a lo largo del tiempo, esa capacidad tiene limitaciones. El gobernante siempre tiene rivales de dos tipos: a) otros Estados deseosos de expandirse y abarcar los recursos y población del primero y b) otro grupo interno potencialmente capaz de hacerse con el poder. Siendo la discusión de ambas limitaciones de gran importancia, para los fines del desarrollo económico, el primero es el que tiene efectos más determinantes en las trayectorias históricas en la que coexisten economías con alta capacidad para la innovación, en tanto que la mayoría carece de ella.

Este determinante (la existencia de Estados rivales deseosos de expandirse) puede modificar los resultados del primero (la tendencia a establecer derechos de propiedad no conductivos a la innovación), pero no en una medida determinista, universal o lineal, porque el acotamiento del poder del gobernante no se puede ajustar a un patrón invariable, de modo que podemos decir que rige la lógica ya explicada de los sistemas complejos. Lo que la historia parece demostrar, añade North, es que ciertas amenazas externas sobre el estatuto del gobernante generarán cambios decisivos en la relación entre el poder y la sociedad, que se traducen en ganancias materiales para los grupos más amplios y para el progreso nacional.

Podemos ver que, al igual que en los sistemas complejos, es posible identificar en el estudio efectuado por North un Estado inicial (el efecto de la constitución del poder en la definición no conductiva a la innovación de los derechos de propiedad en el ámbito nacional), la fuerte tendencia histórica a mantener la trayectoria original, pero coexistiendo con ella, así como una gama de fuerzas tanto internas como externas que pueden alterar la trayectoria, rompiendo el lock in del sistema.

Desde esta perspectiva analítica, Hoff y Stiglitz han extendido el estudio de North a los problemas del desarrollo que es importante para completar nuestra explicación de la persistencia de la trampa del atraso, o la aversión a la innovación. La emergencia del mundo occidental significa que gracias a una gama de fuerzas se rompió el lock in feudal. Ello posibilitó que los países europeos encabezados primero por Holanda y luego Inglaterra siguieran una nueva trayectoria crecientemente orientada a la innovación, sentando una de las bases de la emergencia del capitalismo industrial. Ese proceso, sin la explicación de los fundamentos históricos originarios, es decir la ruptura del lock in, ha sido ampliamente descrito, analizado y discutido por los historiadores de la tecnología, del crecimiento y de desarrollo.

North y Thomas se sitúan en la Europa en el siglo XIV para ilustrar la acción de las fuerzas anteriormente señaladas. ${ }^{12}$ De acuerdo con esos autores, la ruptura del

12 Es preciso hacer esta digresión histórica porque el atraso económico a inicios del siglo XXI implica una forma específica de lock in, que trae a colación el proceso europeo en la baja Edad 
lock in del feudalismo se debe a una especie de choque "exógeno", ${ }^{13}$ que consistió en un descenso demográfico absoluto en Europa provocado por una combinación de hambre generalizada con epidemias que se presentaron de manera intermitente a lo largo del siglo XIV e inicios del XV. El acontecimiento más espectacular, continúan, fue una combinación entre la peste negra, la peste bubónica y la neumónica entre 1348-1351, proveniente de Crimea. La decadencia demográfica europea parece haberse extendido casi un siglo de 1350 a 1470. La repercusión más importante fue el aumento del precio de la mano de obra en relación con el precio de la tierra (op cit.). En otras palabras, la decadencia demográfica significó una conmoción social de una escala mucho mayor al cambio de la tecnología militar en el mundo antiguo, que reconfiguró la relación de todos los elementos que intervienen en la reproducción social. Cabe resaltar, como apuntan North y Thomas, que la subsiguiente desintegración de la servidumbre feudal desencadenó una amplísima movilización social que condujo a la llamada revolución agrícola y a una gama enorme de microinvenciones, que constituyeron el fundamento de la revolución industrial inglesa y el advenimiento del capitalismo industrial.

La hipótesis de North y Thomas, concerniente a la emergencia del mundo occidental, deja abiertas diversas interrogantes. Como lo ha documentado una corriente muy vigorosa de historiadores, ${ }^{14}$ el mundo de la baja Edad Media en Europa estaba distante de la creatividad e innovación pero se benefició de las capacidades existentes en China. Durante los siglos XI a XIV la sociedad china generó una corriente extraordinaria de innovaciones que abarcan desde la metalurgia a la navegación (Mokyr, 1993). Esa capacidad de innovación declinó paulatinamente, pero se difundió por diversos canales a Europa, donde encontró entusiastas receptores cuya mentalidad abierta los inclinaba a tomar del mundo exterior todo aquello que fuera útil o novedoso. ${ }^{15}$

Media y por tanto la interrelación entre la trampa mathusiana (equivalente a la trampa de atraso de Myrdal) y las fuerza de ruptura, que para el caso del siglo XX se discuten en la siguiente sección.

13 North no usa el concepto de choque o conmoción para referirse al cambio en la estructura de los derechos de propiedad y en los otros fundamentos de la reproducción social; el concepto de choques se le debe a Hoff y Stiglitz en la citada obra.

14 Aunque la capacidad de ese país pionero se perdió, sus logros, sumados a la difusión del conocimiento científico en Europa promovida por los árabes (Stokes, 2002), favorecieron la emergencia de la Europa moderna, en especial desde el Renacimiento. El Renacimiento, como parte de la movilización social posterior al choque exógeno, permitió la revaloración de la producción y creatividad individual y la idea de necesidad de bienes comunes que promuevan la innovación y el desarrollo. En este contexto, la innovación fue vista como una nueva fuente de riqueza en el marco de una especialización productiva con rendimientos crecientes derivados del aumento de población en las ciudades y de la división del trabajo asociada (Reinert, 2007).

15 Éste es un rasgo cultural decisivo, como hace hincapié Mokyr (1993), que diferencia la matriz cultural europea de la China antigua (no la de Japón), en cuanto a la curiosidad y receptibilidad 
Lo que parece haber representado una ventaja decisiva para Europa en comparación con China fue la fragmentación político-territorial que dio lugar a la multiplicidad de Estados-nación, en continua competencia y, por tanto, dispuestos a utilizar la creatividad social como instrumento de sobrevivencia y ruptura del status quo.

Este proceso de competencia por la supremacía entre los emergentes Estadosnación puede describirse desde la lógica de los sistemas complejos porque no hubo linealidad, sino retroalimentación positiva y shocks exógenos (Arthur, 1989). Desde esta lógica, algunas regiones profundizaron su conocimiento científico y tecnológico, desarrollaron instituciones conductivas a la creatividad social y se insertaron en la división internacional del trabajo, a partir de la elección de las actividades con rendimientos crecientes a escala. En los casos exitosos ello favoreció el crecimiento de las ciudades y la ampliación del tamaño de mercado, lo que permitió una mayor diversidad productiva y una profundización de la división del trabajo. En la conformación de la Europa moderna los emergentes Estados-nación que parecían destinados a ser líderes se convirtieron en "segundones" (según la expresión de North y Thomas, op. cit.). En lugar de ser España ${ }^{16}$ fue Inglaterra ${ }^{17}$ la que se convirtió en el líder, cerrando la brecha con Holanda y Venecia (Reinert, 2007). En los siglos posteriores Alemania y Francia lograron alcanzar a Holanda e Inglaterra sobre la base de un modelo basado en las sinergias entre rendimientos ascendentes y el crecimiento de las ciudades y el desarrollo del sector manufacturero.

En este sentido, la historia muestra casos contrapuestos en los que los efectos de retroalimentación entre capacidades y vinculaciones conducen por un lado a la gene-

que contrasta con la vieja actitud china de considerar todo lo externo como muestra de barbarie, que debe ser repudiado. Conexo a ese rasgo cultural está, como lo señala atinadamente Rosenberg (1993), la convicción occidental de que la naturaleza es el laboratorio del ser humano, sobre el que tiene derecho ilimitado de explotar a su arbitrio, rasgo considerado extraño en las sociedades orientales.

16 El caso de España es visto en la literatura de la época como ejemplo del tipo de economía y política económica que una nación debería evitar. En oposición a Inglaterra, en vez de proteger la manufactura a fines del siglo XVI, España protegió su producción agrícola y se desindustrializó a partir de ese momento. La idea de que la manufactura es la verdadera mina de oro está presente en casi todos los economistas presmithianos desde 1500 hasta bien avanzado el siglo XVIII que planteaban la relevancia de dos diferentes instituciones claves que definen la estructura de derechos de propiedad: la protección del nuevo conocimiento mediante patentes y la apropiación de ese conocimiento a partir de la política comercial.

17 La Inglaterra de los Tudor de 1485 logró el catching up con Holanda a partir de i) una política explícita para desarrollar la manufactura, sacar provecho del comercio exterior y de las rentas de materias primas basadas en algodón. En este caso, el desarrollo económico se basó en un proceso colectivo de rent seeking, originado en feedbacks positivos entre rendimientos crecientes en la manufactura de algodón, innovación y división creciente del trabajo. 
ración de nuevas capacidades y, por otro, a la destrucción y desindustrialización. El enfoque de sistemas complejos apoya el estudio del cambio institucional, ayudando a explicar cómo la construcción de capacidades asociadas a los procesos de destrucción creativa, cambio estructural y apropiación, devienen en crecimiento económico y desarrollo sólo en algunos casos en los que se cumplen las condiciones políticas ya expuestas.

Como veremos a continuación, al incorporar el planteamiento de Hoff y Stiglitz, en la trayectoria de los latecomers exitosos del siglo XX se advierte que fue decisivo también un choque o conmoción que cambió la forma de funcionamiento de la sociedad y con ello dio paso a la constitución de una matriz institucional proclive a la innovación, el canon de lo que hoy conocemos como el milagro asiático. Sin embargo, como sabemos, ésa es la excepción a la regla, ya que en la mayoría de los latecomers persisten instituciones no conductivas al aprendizaje y a la innovación.

Hoff y Stiglitz plantean que el lock in institucional al que hicimos referencia en el caso europeo también está presente en el desarrollo tardío actual y constituye el fundamento del círculo vicioso de la pobreza: en un momento pasado se creó en un país pobre una estructura institucional adversa enteramente o parcial a la innovación o al aprendizaje que limitó la posibilidad de abrir un sendero de desarrollo. Hoff y Stiglitz hablan de mecanismos culturales de transmisión intergeneracional, que limitan, por ejemplo, el acceso a la educación o al crédito, ingredientes indispensables para la generación de capacidades que den lugar al desarrollo económico. ${ }^{18}$ En este sentido, las diferencias iniciales persisten por un proceso de retroalimentación positiva, pero a diferencia del crecimiento retroalimentado, en este caso es la pobreza y la distribución desigual de la riqueza las que se perpetúan. La trampa del atraso prevalece porque los mecanismos de exclusión se institucionalizan, o sea, dan lugar a reglas formales e informales que sirven a ese fin, moldeando la conducta, las competencias y capacidades de los agentes e instituciones y la visión colectiva de la realidad social.

Los historiadores de la escuela de Stanford (véase Engerman y Sokoloff, 1997 y Grief, 2002) sugieren que el punto de partida de lo que aquí llamamos el lock in institucional que pesa sobre América Latina se encuentra en general en la inserción

18 Estos autores señalan que “...un individuo con ninguno o pocos activos podría ser relativamente improductivo... y si existen muchos individuos con ninguno o pocos activos, las tasas salariales serán bajas. Con salarios bajos, los individuos con riqueza baja desde el inicio dejarán poca herencia a la próxima generación. Por ello, una distribución altamente desigual de la riqueza como la que caracteriza a América Latina puede durar siempre y puede limitar permanentemente el crecimiento" (op. cit., p. 395). 
colonial que se reforzó a raíz de la expansión capitalista en el último cuarto del siglo XIX. Sin embargo, esos autores resaltan que no hay una relación determinista, sino modalidades o vías de inserción al sistema colonial. La modalidad más desfavorable al desarrollo parece ser aquella en que la abundancia de recursos naturales propicia el aprovechamiento inmediato de las rentas del suelo, lo que en general se asocia a la instauración de una economía que Jonathan Levin (1971) llama de enclave de exportación y que los historiadores latinoamericanos han caracterizado por su legado de despotismo y fuerte polarización social (sobre la aplicación del concepto de vía de desarrollo, véase Dabat 1994).

Al convalidar la existencia de una relación no determinista o lineal entre el desempeño económico y los choques o conmociones que pueda sufrir una sociedad, nos encontramos que esto último puede ser contraproducente al generar la destrucción de instituciones avanzadas o superiores (Hoff y Stiglitz, op. cit., p. 419). La clave parece radicar, por tanto, en el tipo e intensidad de conmoción, ya sea interna o externa, y en la forma como la sociedad reacciona a la misma. Como lo refrenda el estudio del dinamismo del mundo occidental, las conmociones que, además de ser profundas sean duraderas, son las que tienen mayor probabilidad de cambiar positivamente el funcionamiento de la sociedad. Una conmoción profunda, pero fulminante, como la derivada de la relación crisis de la deuda-reforma neoliberal en América Latina, tendió a desencaminar los procesos de movilización social y con ello entorpeció los mecanismos de aprendizaje colectivo (véase el siguiente apartado). Igualmente los choques poco profundos no colocan a las élites ante la necesidad de reformas de mayor alcance (véase Cimoli y Rovira, 2008), en tanto no implican una amenaza a su poder. ${ }^{19}$ Además, como explican Hoff y Stiglitz, partiendo de un lock in, las élites políticas tienden a actuar de manera racional (evalúan el impacto futuro de las reformas sobre el equilibrio del poder actual). ${ }^{20}$ Dicho de otra manera, aunque una reforma puede generar beneficios para todos, las élites la descartarán porque asumen que provocará una serie de repercusiones que les pueden arrebatar el poder. Como había planteado Evans mucho antes (1995), la racionalidad de las élites latinoamericanas es

19 El tema de si las élites en América Latina se han renovado tras las crisis de los años ochenta y noventa y en qué proporción lo han hecho, más la definición de la relación entre el régimen anciano y el actual, es crucial, pero su discusión rebasa los objetivos de este artículo.

20 Esta posición se encuentra también en Antonelli (2007) cuando plantea que los cambios sólo son posibles cuando estas conmociones producen mismatch entre expectativas y condiciones objetivas de la dinámica económica. Si estos mismatch son muy pequeños o muy grandes, los incentivos al cambio son bajos. 
consustancial al status de Estado depredador, en tanto el mayor enemigo del progreso son los grupos que detentan el poder, que no tendrían cabida en una sociedad más próspera y dinámica. En la misma dirección, es posible pensar que cuando los grupos que detentan el poder están asociados a actividades con rendimientos decrecientes y escasas sinergias, por ende con derechos de propiedad "ineficientes", el modo de inserción internacional limita las posibilidades de desarrollo.

En contraste con el clima propicio a la depredación, una conmoción profunda y más duradera, por ejemplo que amenace la sobrevivencia nacional, probablemente provocará lo que Hoff y Stiglitz llaman intervenciones estatales profundas. En esa dirección, la preservación del poder en su sentido más amplio implicará cesión del mismo a la base de la sociedad, abriendo con ello la posibilidad de la movilización en la que se basa el desarrollo. En tal caso podríamos hablar de un proceso de destrucción creativa activada por un choque, cuya canalización como cambio estructural depende de la forma en que se movilice la sociedad y se generen paulatinamente estructuras de derechos de propiedad que favorezcan a las actividades con rendimientos crecientes, innovación y spill-overs tecnológicos. De existir esas condiciones políticas, es clave el proyecto estratégico del grupo que detenta el poder, que para aumentar las capacidades de absorción y conectividad deberá modificar la estructura de los derechos de propiedad. El otorgamiento de patentes, aranceles que promuevan el aprendizaje y otros instrumentos de política comercial, pueden dar lugar a sinergias, rendimientos crecientes, ampliación del mercado interno y profundización de la división del trabajo, lo que en conjunto puede generar una tasa mayor de crecimiento y el catching up.

En síntesis, el desarrollo económico requiere un proyecto estratégico y la movilización social, que a su vez — partiendo de situaciones de lock in que traban el desarrollo de las capacidades de absorción y conectividad- depende de un cambio que afecte la estructura del poder y permita la construcción de instituciones superiores o conductivas a la creatividad y a la innovación social e individual. ${ }^{21}$ En consecuencia, la fuerza más conductiva al progreso es una suerte de amenaza persistente sobre el gobernante o sobre los grupos que detentan el control del Estado. Ese proceso complejo es el que crea la diferencia entre el Estado depredador y el Estado como impulsor del desarrollo. Así formulado, este postulado es la base teórica de lo que Hoff y Stiglitz llaman una nueva teoría del desarrollo, que explicaría no sólo el dinamismo del mundo occidental, sino también el ascenso de los Tigres Asiáticos, de China e India; explicaría también la persistencia del atraso en los países del tipo $B$.

21 En North, pero conceptualmente en el tratamiento que efectúan Hoff y Stiglitz, esa forma fundamental de conmoción es exógena, pero en realidad, si consideramos a la economía nacional en el marco mundial, es endógena porque es parte de la relación orgánica entre ambas. 
Cambio institucional y capacidad de innovación: una referencia comparativa al caso de América Latina

\section{Hacia una agenda tentativa de investigación}

Lo que sigue en calidad de conclusión es un ejercicio teórico-analítico prospectivo para abrir una discusión más amplia y proponer temas a investigar, desde una perspectiva comparativa, tomando como base inmediata los apartados anteriores. Además de asumir como eje conductor la exposición de North-Nueva Teoría del Desarrollo, complementada con elementos clave de la teoría de los sistemas complejos, nos apoyaremos en el tratamiento del desarrollo tardío (Hikino y Amsdem, 1995; Amsden, 1989; Wade, 1999). La hipótesis de las ondas mundiales de desarrollo de Pérez (2004) y de cambio histórico (Dabat, 2002) constituyen también parte del marco referencial sistémico con el que cerraremos la exposición. Hay aportaciones

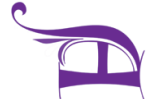
individuales y, en cierto modo, avanzadas para su tiempo como la de Evans que mantendremos en mente. Las limitaciones de espacio hacen inevitable el esquematismo y explican la renuncia a profundizar la relación entre la teoría del cambio institucional y la de los sistemas complejos, pero no obstante el reconocimiento de ese nexo es crítica en esta parte de la exposición. A pesar de ello, consideramos que las nociones de dependencia de sendero, retroalimentación y simultaneidad en la determinación micro-macro e institucional en contextos de desequilibrio constituyen los conceptos "puente" que articulan ideas básicas del enfoque institucionalista y evolucionista. En este punto de la exposición es oportuno ilustrar factualmente la diferencia entre los países tardíos del tipo $A$ y del tipo $B$, que se condensa en el cierre/ampliación de la brecha internacional (véase cuadro 1 ).

Lo señalado en la sección anterior nos propone una breve explicación teórica e histórica de la persistencia de las instituciones contrarias a la innovación y al aprendizaje y el efecto de los choques o conmociones sociales. La limitada capacidad de innovación que muestran las empresas latinoamericanas pone de manifiesto la persistencia de las trayectorias institucionales adversas y corrobora empíricamente la ausencia de conmociones profundas y duraderas, ${ }^{22}$ así como de procesos de especialización que no requieren instituciones superiores ni el desarrollo de capacidades avanzadas.

Para avanzar en la exposición habría que poner de manifiesto cómo las conmociones que han sufrido los países de América Latina en el siglo XX y hasta en la ac-

22 Consideramos una atenuante de la conmoción a un nuevo auge basado en la renta del suelo, rasgo recurrente de la historia latinoamericana. 
Cuadro 1

Indicadores del desarrollo tardío, 18202004 PIB per capita en dólares constantes y sus tasas de crecimiento; cierre/ampliación de la brecha internacional (dólares de 1990)

\begin{tabular}{lrrrrrrr}
\hline & & & & \multicolumn{5}{c}{$\begin{array}{c}\text { Brecha internacional \% * } \\
\text { Países representativos tipo A }\end{array}$} & 1820 & 1900 & 1950 & 1992 & Hasta 1950 & Hasta 1992 & Hasta 2004 \\
\hline Corea del Sur & & 850 & 876 & 10,010 & 9.00 & 46.00 & 51.00 \\
Taiwán & & 759 & 922 & 11,590 & 9.60 & 53.70 & \\
Singapur & 1,063 & 2,040 & 2,397 & 12,498 & 24.70 & 58.00 & 63.60 \\
España & 1,100 & 1,354 & 2,132 & 11,130 & 22.20 & 51.60 & 48.40 \\
Portugal & & & & & & & \\
Países representativos tipo B B & & & & & & & \\
\hline & 1,311 & 2,756 & 4,987 & 7,616 & 52.0 & 35.0 & 31.30 \\
Argentina & 670 & 704 & 1,673 & 4,637 & 17.40 & 21.50 & 20.20 \\
Brasil & 760 & 1,157 & 2,089 & 5,112 & 21.70 & 23.70 & 24.10 \\
México & & 1,949 & 3,827 & 7,238 & 39.90 & 33.50 & 26.90 \\
Chile & 614 & 745 & 874 & 2,749 & 9.10 & 12.70 & 8.70 \\
Indonesia & & 1,033 & 1,293 & 2,213 & 13.50 & 10.00 & 12.30 \\
Filipinas & & & & & & & \\
\hline
\end{tabular}

* La brecha internacional se mide como la participación porcentual del PIB per capita del tardío respecto al PIB per capita de EU.

Fuente: Maddison, 1997, Apéndice D; World Bank 2006, Anexo Estadístico.

tualidad los choques han resultado contraproducentes, tal vez porque, como plantea Antonelli, generen un mismatch entre las expectativas de los agentes y los datos objetivos de la estructura económica que desalientan los procesos de movilización social. Por ser fulminantes las conmociones a las que nos estamos refiriendo, provocan fuertes desajustes sociales, entre los que sobresale la mayor concentración del ingreso y la consolidación de la posición conservadora de las élites. La razón es que esos efectos sociales desestructuran la movilización de base, tienden a nulificar la voz y promueven las acciones individuales.

En términos generales y sin atenernos a las diferencias nacionales, los países de América Latina experimentaron la conmoción provocada por el agotamiento de la ISI. A su vez, la crisis de la deuda y la bancarrota del sector público que caen en la categoría de fulminantes limitan las capacidades creativas de los agentes por las razones arriba expuestas. A continuación vinieron las reformas neoliberales, que en sí representan otra forma de choque fulminante. En todos estos casos, dado el tipo de matriz institucional predominante, los esfuerzos de innovación fueron básicamente incorporados y por tanto tuvieron fuertes limitaciones para el desarrollo de las capacidades de absorción y conectividad de las organizaciones. A pesar de que las 
reformas produjeron una importante transformación en la estructura productiva de la región, ello no implicó ni el desarrollo de procesos de cambio estructural en el sentido de Ocampo, o empíricamente como los tardíos del tipo $B$ (sobre los jugadores contra las reglas véase más adelante). En ese sentido, los procesos de destrucción creativa y apropiabilidad, que son precondición de las conductas innovadoras en las firmas, han estado en general ausentes o han sido intermitentes.

De acuerdo con lo señalado en el apartado anterior, el resultado "óptimo" de una conmoción o choque radica en cambiar el balance de poder en favor de los grupos más dinámicos con capacidad de promover el cambio estructural. Cabría resaltar que el tipo fundamental de conmoción que afecta el balance de poder debe interpretarse en el sentido de Gramsci, de amenaza al bloque histórico nacional, o sea, al poder y a sus fundamentos materiales de reproducción (que en casos extremos implica la capacidad de mantener la integridad nacional). En tal situación, como ya señalamos, para mantener la estructura de poder se requerirá hacer uso de expedientes nuevos, el más fundamental de los cuales es la movilización de la sociedad en su conjunto, a fin de incrementar las capacidades de absorción y conectividad de los agentes y promover procesos de destrucción creativa, apropiación de rentas dinámicas y cambio estructural. Por ende conceptualizaremos la movilización social y la movilidad de recursos ocultos en el sentido de Hirschman (1964) como el otro fundamento del crecimiento económico moderno.

En este punto es donde podemos establecer la diferencia de trayectoria entre los países tardíos del tipo $A$ (países tardíos exitosos) y las economías más grandes de América Latina, pertenecientes al tipo $B$.

En consecuencia, procederemos al diferenciar una fuerza de primer orden ${ }^{23} \mathrm{y}$ fuerzas de segundo orden que concurren en el cambio socioeconómico. Los países que más han progresado económicamente en Asia son lo que, a partir de determinadas condiciones "objetivas" favorables, fueron sometidos a una muy persistente o continua amenaza externa a la integridad nacional y a la élite en el poder (fuerza de primer orden). Ello, frente a determinados factores detonantes (fuerza de segundo orden), condujo a generar condiciones actuales y potenciales para la movilización social (también fuerzas de segundo orden). La más importante de esas condiciones fue el "Estado desarrollista" definido por Amsden y Wade. Empero existen otras instituciones pro innovadoras como una administración pública con cierto grado de

23 La fuerza de primer orden es la amenaza persistente a la integridad nacional que activa la movilización social. 
eficiencia (India) y frecuentemente el cultivo de la ciencia con fines defensivos (casos de India y China).

Por ende, en los países asiáticos que experimentaron un asombroso progreso económico a fines del siglo XX e inicios del actual no parecen apegarse a un modelo único de fuerzas secundarias, pero sí de una fuerza primaria. Esa fuerza primaria produjo un impacto positivo en el perfil de especialización y en la modalidad de inserción internacional, lo que gracias a la concurrencia de rendimientos crecientes, externalidades y apropiación de rentas económicas consolidó la posición de las fuerzas favorables al cambio, ya sea que se sitúe en la estructura de poder o en la base organizativa.

Las oportunidades de especialización exitosa en los países que lograron el sustento institucional requerido fueron especificadas por Amsden (1989) al ubicarlas en las industrias "adolescentes o intermedias", que, pese a su proximidad a la madurez, generan rentas económicas que favorecen la continuidad del desarrollo. En este caso, es decisiva una fuerza secundaria: el sistema educativo que favoreció la formación masiva de ingenieros de producción, cuyo foco de atención está en el shopfloor, para supervisar la adaptación de la tecnología importada. Pero en sí, la formación masiva de ingenieros no es el punto de partida para explicar el desarrollo en Corea del Sur. En una sociedad con alto grado de atraso económico y social, el impulso a la formación masiva de ingenieros y técnicos vino de un cambio decisivo en la estrategia estatal, que es el resultado de la acción de la fuerza de primer orden. Pero ¿por qué el Estado cambió su orientación depredadora (su status natural) a una orientación desarrollista? La respuesta general es la que se ha ofrecido a lo largo de toda la exposición anterior. $^{24}$

En el caso de Corea del Sur como en Taiwán, la fuerza de primer orden, o sea el factor que posibilita la movilización social (vía educación, correlación entre productividad y salarios, etcétera), fue la amenaza proveniente de la insurrección comunista, que adquiere condición crítica por ubicarse en la frontera entre el mundo comunista y el capitalismo. ${ }^{25}$ En el caso de China comunista lo es sobre todo la amenaza de las

24 Pese a sus invaluables aportaciones, la omisión de la literatura desarrollista encabezada por Amsden radica en no plantear la fuerza de primer orden en Asia Nororiental y empezar por las de segundo orden: el Estado desarrollista, dejando abierta la pregunta de por qué el desarrollismo fracasó en nuestra región. Hasta cierto punto es natural que este enfoque haya desconcertado a algunos autores en América Latina, que adoptaron un enfoque normativo: ha prevalecido la trampa del atraso porque el Estado no adoptó la estrategia asiática.

25 Proponemos la hipótesis de que la proximidad al punto de conflicto o a la amenaza es determinante en la magnitud de los efectos en la estructura de poder y por ende en las posibilidades 
potencias occidentales y en India la amenaza persistente de China y las secuelas de la llamada "partición". Pese a su estado de atraso y pobreza durante la época maoísta, China preservó ciertos rasgos institucionales que detonan al insertarse a la globalización; probablemente el más importante de ellos fue el cultivo de la ciencia que es la base actual del desarrollo de microelectrónica, computación y nanotecnología.

En contraste, Indonesia y Filipinas experimentan una amenaza externa atenuada (la débil insurrección guerrillera) que fortaleció la represión, el monopolio del poder, la corrupción y el Estado cleptómano (con Ferdinand Marcos y Suharto). ${ }^{26}$

En lo que concierne a los efectos de la fuerza de primer orden, los países de América Latina comparten con Indonesia y Filipinas la atenuación de la amenaza externa, pero además la generosidad de la naturaleza ha trastocado el papel impulsor de las condiciones objetivas iniciales, condicionando su modalidad de inserción al sistema colonial que llamamos en el apartado anterior y siguiendo a Levin de enclave. Al ser intermitente la fuerza primaria, la movilización social y su estructura institucional ha sido precaria e incompleta.

Como vimos, el patrón recurrente en América Latina a lo largo del siglo XX y hasta el presente ha sido la sucesión de conmociones o choques endógeno/exógenos. A consecuencia de los efectos fulminantes, comienzan a efectuarse reformas sociales que podrían favorecer cierta movilización social posterior (impulso a la educación, la construcción o modernización de la infraestructura, la ampliación de la democracia-derechos civiles, el acceso al crédito, la creación de pequeñas empresas, etcétera) y se empiezan a crear instituciones "superiores". Empero, la duración del proceso de construcción institucional depende de la aparición de un nuevo auge de la renta internacional del suelo, que acota la complejidad del emergente sistema institucional (Dabat et al., 2007). Podemos decir que el auge de la renta de la tierra limita la emergencia de los procesos y capacidades que caracterizan a un sistema complejo. En ese contexto es más probable que las instituciones inferiores destruyan o limiten a las superiores (véase Hoff y Stiglitz, op. cit.). En rigor, los choques fulminantes a los que nos estamos refiriendo tienen orígenes tanto exógenos como endógenos. Por un lado, el choque definitivo que pone fin al desarrollo de instituciones superiores

de movilización social. Ello marca una diferencia entre los Tigres Asiáticos y el resto de los países en desarrollo, donde también existían procesos insurrecciónales que fueron combatidos directamente.

26 Como lo señala Amsden (1989) así como Kang (2002), los Tigres Asiáticos, incluso durante la etapa de desarrollo acelerado, sufrieron secuelas graves de corrupción. Sin embargo, a diferencia de Filipinas, por ejemplo, fue hasta cierto punto funcional a la rápida industrialización y fue acotada con medidas gubernamentales drásticas. 
vinculadas a la especialización de la ISI es exógeno (crisis de la deuda, colapso de mercados, contagio financiero, etcétera).

Por otro lado, hay endogenidad en el hecho de que las élites se vinculan preponderantemente a la apropiación de renta financiera por medio de circuitos externos, limitando el aprendizaje y la acumulación de capacidades tecnológicas en los sectores productivos de mayor complejidad (Sábato, 1988), lo que aumenta la vulnerabilidad a los choques exógenos. Al apegarse a esta estrategia contribuyen a mantener el perfil de especialización existente.

Sin embargo, es importante otra secuela del anterior proceso, que puede incluir elementos de destrucción creativa y no sólo destructiva (en el sentido de Reinert). Muchos individuos con capacidad y talento (que gozan de los beneficios de los avances parciales en el sistema institucional) eligen la "salida" para usar la expresión de Hirschman, debido a que sus capacidades no son compatibles con la matriz institucional y la base organizativa-productiva existente en los países del tipo $B$. Pero si se logra una masa crítica y condiciones favorables en los países receptores, pueden ser el foco de diásporas que favorezcan el aprendizaje al establecer circuitos que reconectan con sus comunidades o localidades de origen (los casos más profusamente estudiados son los de Taiwán e India, pero se reconoce la importancia de los brasileños y argentinos en el extranjero). ${ }^{27}$

Pero no sólo cuentan los que eligen la "salida", cuentan los que eligen la "voz", que en la tipología de North se les califica como jugadores contra las reglas (North, 1993). También la sucesión entre creación/destrucción institucional deja nichos de creatividad que pueden favorecer el aprendizaje, la educación, el cultivo de la ciencia, etcétera. Muchos de esos nichos adquieren constitución organizacional y pueden sobrevivir hasta cierto punto en un medio hostil para desempeñar la función de organizaciones puente a las que se refiere Casalet (2000).

En el caso de los jugadores contra las reglas ${ }^{28}$ el éxito radicaría en su oposición a las élites dominantes, para constituir la semilla de otras nuevas, cuya fuente de renta esté centrada en sus esfuerzos de innovación. ${ }^{29}$ Pero ese éxito no está garantizado, los

27 No obstante, de ninguna manera habría que considerar que esas diásporas son necesariamente generadoras de bienes públicos; tenemos el caso de la diáspora somalí que ha convertido la piratería en el Golfo de Adén en una industria moderna; igualmente se reconoce una suerte de diáspora mexicana ligada a la criminalidad.

28 La regla básica es no innovar.

29 En Argentina la conmoción provocada por la crisis de la caja de convertibilidad tuvo efectos ambivalentes, pero favoreció cierto grado de unificación de los jugadores contra las reglas y los nichos institucionales, en sectores "nuevos" (servicios de software y biotecnología, entre otros). 
jugadores positivos contra las reglas no abundan y tienen limitado poder de negociación, además de que tienden a ser manipulados por los poderes tradicionales.

$\mathrm{Al}$ sintetizar las secuelas, es posible pensar que una vía de progreso se abre al interrelacionarse la acción de las diásporas, los jugadores positivos contra las reglas y los nichos institucionales. Los países más grandes de América Latina muestran en diferente grado islotes de creatividad derivados de la acción de los factores anteriores. Si se tratara de apuntar a un país que parece haber avanzado más en esta dirección, Brasil es la elección más obvia, aunque no exenta de controversia. Al tomar como punto de apoyo los trabajos de Evans, diremos que el factor más relevante ha sido cierta continuidad de las conmociones, que dieron como resultado el mantenimiento de una mayor integridad institucional, el cultivo de la ciencia y la apertura de vías de movilización social. En comparación, Argentina y México sufrieron un mayor grado de destrucción institucional.

La enorme desigualdad social que caracteriza a Brasil es un factor ambivalente. Por un lado, dificulta la movilización social, pero la amenaza de una rebelión, nunca enteramente atenuada, obliga a las élites en el poder a establecer contrapesos que garanticen cierta movilidad y por ende la continuidad del cambio institucional. Empero, el mismo proceso de ruptura del círculo vicioso de la pobreza puede significar desequilibrios nuevos; por ejemplo, en el sistema educativo. El esfuerzo en educación superior, para mantener el impulso de la ciencia, implicó desatender la calidad de la educación básica, lo que ha ido en detrimento de la población más pobre y en consecuencia limita el desarrollo de capacidades claves para promover procesos de destrucción creativa, cambio estructural y apropiabilidad.

Finalmente, cabe destacar la incidencia de la economía mundial o global. Los autores citados raras veces toman en cuenta la incidencia de los factores internacionales, que aquí aludimos como "factores detonantes". La excepción a esta regla es Carlota Pérez (véase también Dabat, 2002).

En el marco de lo que Pérez (2001) llama la doble ventana de oportunidades, el paulatino avance hacia la integración global de la producción elevó de manera dramática la transferencia internacional de conocimiento tecnológico, cambiando enteramente el entorno de las economías tardías (Ernst y Kim, 2000). Ambos autores pasan en seguida a centrar su atención a la "capacidad de absorción", pero circunscribiéndola al espacio local, no al nacional. Ciertamente lo que crea la diferencia entre las economías tardías del tipo $A$ frente a las del $B$ es la capacidad de absorción y conectividad, pero entendida además como transformación de la matriz institucional $\mathrm{y}$, por ende, mediada por el ejercicio del poder y el funcionamiento de la sociedad. 
Sin embargo, la perspectiva abordada de sistemas complejos permite enriquecer las determinaciones y tomar en cuenta propiedades emergentes que pueden manifestarse tanto en el nivel micro cuando el análisis es agregado, como en el nivel macro, cuando se estudian las dimensiones micro y mesoeconómicas determinantes de las capacidades de absorción y conectividad de los agentes.

\section{Bibliografía}

Acemoglu, Daron, S. Johnson y A. Robinson, "The Colonial Origins of Comparative Development: An Empirical Investigation", en American Economic Review, vol. 91, núm 5, Broadway, AEA, diciembre de 2001, pp. 1369-1401.

Amsden, Alice, The Rise of the 'Rest'. Challenges to the West from Late-Industrializing Economies, Nueva York, Oxford University Press, 2001.

, Asia's Next Giant: South Korea and Late Industrialization, Nueva York, Oxford University Press, Oxford, 1989.

, y Wan Chu, Beyond Late Development: Taiwan's Upgrading Policies, Cambridge, MIT Press, 2003.

Antonelli, Cristiano, "Technological Knowledge as an Essential Facility", en Journal of Evolutionary Economics, vol. 17, núm. 4, agosto de 2007, Netherlands, Springer Science \& Business Media B.V., pp. 451-471.

, The Microeconomics of Technological Systems, Oxford, Oxford University Press, 2001.

, "The Evolution of Industrial Organization in the Production of Knowledge", Cambridge_Journal of Economics, vol. 23, núm. 2, Oxford, Oxford University Press, marzo de 1999, pp. 243.

Arrow, Kenneth. "Economic Welfare and the Allocation of Resources for Invention", en Mirowski, Philip y Esther-Mirjam Sent (eds.), Science Bought and Sold. Essays in the Economics of Science, Chicago, The University of Chicago Press, 2002.

Arthur, W. Brian, "Competing Technologies, Increasing Returns, and Lock-In by Historical Event", en The Economic Journal, vol. 99, núm. 394, Oxford, Blackwell Publishing Limited, marzo de 1989, pp. 116-131.

"Competing Technologies: An Overview" en G. Dosi, C. Freeman, R. Nelson,
G. Silverberg y L. Soete (eds.), Technical Change and Economic Theory, eds. Pinter, London.

Steven N. Durlauf y Davd Lane. The Economy as an Evolving Complex System II, Massachusetts, Perseus Books, 1997.

Banerjee, Abhijit, "Information, the Dual Economy and Development", Review of Economic Etudies, núm. 65, octubre de 1988.

Bell, Martin y K. Pavitt, "Accumulating Technological Capability in Developing Countries", Annual Conference on Development Economics, 1992.

Benavente, José Miguel, Gustavo Crespi, Jorge Katz y Giovanni Stumpo, "La transformación del desarrollo industrial de América Latina", en Revista de la CEPAL, núm. 60, Santiago de Chile, CEPAL, diciembre de 1996, pp. 49-72.

Björn, Johnson, Lorenz, Edward y Lundwell, Bengt-Åke, "Why all this fuss about codified and tacit knowledge?", en Industrial and Corporate Change, vol. 11, núm. 2, Oxford, Oxford University Press, abril de 2002, pp. 245-262.

Blaug, Mark, The Methodology of Economics or: How Economists Explain, Cambridge, Cambridge University Press, 2002.

Booker, Lashon, Stephanie Forrest, Melanie Mitchell y Rick Riolo, "Introduction”, en Lashon Booker et al. (eds.), Perspective on Adaptation in Natural and Artificial Syste$m s$, A Volume in the Santa Fe Institute Studies in the Science of Complexity, Oxford, Oxford University Press, 2005.

Cimoli Mario y Sebastián Rovira, "Elites and Structural Inertia in Latin America: An Introductory Note on the Political Economy of Development", en Journal of Economic Issues, vol. 42 núm. 2, Bucknell University Lewisburg Pennsylvania, junio de 2008.

Cohen, Wesley M. y Levinthal, Daniel A., " Innovation and Learning: The Two Faces of 
R \& D", The Economic Journal, vol. 99, núm. 397, St. Andrews, UK, Blackwell Publishing for the Royal Economic Society, septiembre de 1989.

Coriat, Benjamin y Giovanni Dosi, "The Instituional Embeddedness of Economic Change: an Appraisal of the 'Evolutionary' and 'Regulationist' Research Programme', en Hodgson, Geoffrey M. (ed.), A Modern Reader in Institutional and Evolutionary Economics, Cheltenham, Edward Elgar Publishing, 2002.

Cowan, Robin, Paul A. David and Dominique Foray, "The Explicit Economics of Knowledge Codification and Tacitness", en Industrial and Corporate Change, vol. 9, núm. 2. Oxford, Oxford University Press, junio de 2000.

Chenery, Hollis, "The Structuralist Approach to Development Policy", en American Economic Review, vol. 65, núm. 2, Nashville Tennessee, American Economic Association, mayo de 1975.

Dabat, Alejandro, Capitalismo mundial y capitalismos nacionales, FCE-UNAM, 1994.

, "Globalización, capitalismo actual y nueva configuración espacial del mundo", en Dabat, Alejandro, Miguel Ángel Rivera Ríos y James W. Wilkie (coordinadores), Globalización y cambio tecnológico. México en el nuevo ciclo industrial mundial, Guadalajara, UdeG-UNAM, UCLA-Program on México, PROFMEX y Juan Pablos Editor, 2002.

, Miguel Ángel Rivera Ríos y Sebastián Sztulwark, "Rentas económicas en el marco de la globalización: desarrollo y aprendizaje. Implicaciones para América Latina”, en Problemas del Desarrollo, vol. 38, núm. 151, octubre-diciembre de 2007.

David, Paul, "Path Dependence, its Critics and the Quest for 'Historical Economics"”, en Garrouste, Pierre y Stavros Ioannides (eds.), Evolution and Path Dependence in Economic Ideas: past and present, Cheltenham, UK, 2001.

Dosi, Giovanni, "Some Thoughts on the Promises, Challenges and Dangers of an 'Evolutionary Perspective in Economics",, en Journal of Evolutionary Economics, vol. 1 núm. 1, enero de 1991, pp. 5-7.

y Y. Kaniovski, "On 'Badly Behaved' dynamics: Some applications of generalized urn schemes to technological and economic change", en Journal of Evolutionary Economics, vol. 4, núm. 2, junio de 1994a. y Richard Nelson, "An Introduction to Evolutionary Theories in Economics", en Journal_of Evolutionary Economics, vol. 4, núm. 3, septiembre de 1994, pp. 153-172.

Engerman, Stanley y Kenneth Sokoloff, "Factor Endowments, Institutions, and Differential Path of Growth Among New World Economics; A View From Economic Historians of the United States", en Stephen Haber (ed.), How Latin America Fell Behind. Essays on Economic Histories of Brazil and Mexico, 1800-1914, Stanford, Stanford University, 1997.

Erber, A., V. Robert y G. Yoguel, Complex Systems and Economic Development, ponencia presentada en el Seminario Internacional, Innovación Tecnológica y Rentas Económicas en las Redes Globales de Producción, México, 6-7 de marzo de 2008.

Ernst, Dieter, Innovación Offshoring. Causas de fondo del ascenso de Asia e implicaciones de política, IIEc-FE/UNAM, COLMEX y Casa Editorial Juan Pablos (en prensa).

y Linsu Kim. 2002. "Global Production Networks. Knowledge Diffusion and Local Capability Formation", en Research Policy, vol. 31, núm. 4, Amsterdam, Elsevier, mayo de 2002, pp. 1417-1429.

Evans, Peter, Embedded Autonomy: States and Industrial Transformation. Princeton, NJ, Princeton University Press, 1995.

Fogel, R. W., "Douglass C. North and Economic theory", en Drobak John N. y John V. C. Nye (eds.), The Frontier of the New Institutional Economics, San Diego, Academic. 1997.

Fajnzylber, Fernando, La industrialización trunca de América Latina, México, Nueva Imagen, 1983.

Freeman, Christopher y Carlota Pérez, "Structural Crises of Adjustment: Business Cycles and Investment Behaviour", en Dosi, Giovanni, R. Nelson, G. Silverberg, y L. Soete (eds.), Technical Change and Economic Theory, Londres, Francis Pinter, 1988, pp38-66.

Gramsci, Antonio, Selections from the Prison Notebooks, Nueva York, Institutional Publisher, 1971.

Greif, Avner, Institutions and the Path to the Modern Economy, Nueva York, Cambridge University Press, 2006.

Hikino T. y Alice Amsden, "Staying Behind, Stumbling Back, Sneaking up, soaring Ahead: Late Industrialization in Historical 
Perspective", en O'Brien Patrick (ed.), Industrialisation: Critical Perspective on the World Economy, vol. II, Taylor \& Francis Group, 1998.

Hirschman, Albet O., La estrategia del desarrollo económico, México, FCE, 1961.

"La economía política de la industrialización a través de la sustitución de importaciones en América Latina", en El Trimestre Económico, vol. LXIII, núm. 2, México, abril-junio de 1996.

Hoff, Carla y Joseph Stiglitz. "La teoría económica moderna y el desarrollo", en. Meier Gerald M., y Joseph Stiglitz (eds.), Fronteras de la economía del desarrollo. El futuro en perspectiva histórica, México, Banco Mundial-Alfaomega, México, 2002.

Holland, John, El orden oculto. De cómo la adaptación crea la complejidad, México, FCE, 2004

Kang, David C., Crony capitalism. Corruption and Development in South Korea and Philippines, Cambridge, Cambridge University Press, 2002.

Katz, Jorge, Una nueva visita a la teoría del desarrollo económico, Santiago de Chile, CEPAL, 2008.

Kuznets, Simon, Crecimiento económico moderno, Madrid, Aguilar, 1973.

Levin, Jonathan, "Las economías de exportación", en Theberge, James. D. (comp.), Economía del comercio y el desarrollo, Buenos Aires, Amorrortu, 1971.

Levinthal, Daniel, "Organizational Adaptation and Environmental Selection: Interrelated process of Change", en Cohen, Michael D. y Lee Sproull (eds.), Organizational Learning, Massachusetts, Thousand Oaks, 1996.

March, James, "Exploration and Exploitation in Organizational Learning", en Cohen, Michael D. y Lee Sproull (eds.), Organizational Learning, Massachusetts, Thousand Oaks, 1996, pp. 101-123.

Marx, Carlos, El capital, vol. I, México, FCE, 1946.

"Prólogo de la contribución a la crítica a la economía política", en Marx, Carlos y Federico Engels, Obras Escogidas, Moscú, Editorial Progreso y Ediciones de Cultura Popular, México, s/f.

Messner, Dirk, The Network Society. Economic Development and International Compertitiveness as Problems of Social Governance, Londres, Frank Cass, 1997.

Metcalfe, S. Foster, J. and Ramlogan, R., "Adaptive economic growth", Cambridge Journal of Economics, núm. 30, 2006.
Mokyr, Joel, "Innovation and its Enemies: The Economic and Political Roots of Technological Inertia" en Olson, Mancur y Satu Kähkönen (eds.), A Not-So-Dismal Science. A Broader View of Economies and Societies, Oxford, Oxford University Press, 2000.

, La palanca de la riqueza. Creatividad tecnológica y progreso económico, Madrid, Alianza, 1993.

Nelson, Richard R., Technology, Institutions, and Economic Growth, Cambridge, Harvard University Press, 2005.

y Winter, Sidney G., An Evolutionary Theory of Economic Change, Cambridge, Harvard University Press, 1982.

Nooteboom, Bart, Learning and Innovations in Organizations and Economies, Oxford, Oxford University Press, 2000.

North, Douglass y Robert Thomas, El nacimiento del mundo occidental. Una nueva historia económica 900-1700, México, Siglo XXI Editores, 1973.

Estructura y cambio en la historia económica, Madrid, Alianza, 1984.

, Instituciones, cambio institucional y desempeño económico, México, FCE, 1993.

,"Prólogo (adaptación del discurso 'mi evolución como economista", en el Trinity Collage, Texas), en Drobak, John y Nye John V. C. (eds.), The Frontiers of the New Institutional Economics, San Diego, Academia Press, 1997.

Ocampo, José A. (coord.), Crecimiento económico y la dinámica de la estructura productiva, Santiago de Chile, 2006.

Pérez, Carlota, Revoluciones tecnológicas y capital financiero, México, Siglo XXI Editores, 2004.

"Cambio tecnológico y oportunidades de desarrollo como blanco móvil", en Revista de la CEPAL, núm. 75, Santiago de Chile, diciembre de 2001.

Porcile, Gabriel, Márcio Holland, Mario Cimoli y Luciana Rosas, "Especialización, tecnología y crecimiento en el modelo Ricardiano" en Nova Economia, vol. 16, núm. 3, Predio da FACE Belo Horizonte, Brazil, Hugo E. A. da Gama Cerqueira, 2006, pp. 483-506.

Rivera Ríos, Miguel Ángel, "Inserción internacional, aprendizaje y coordinación en México", en A. Dabat, Alejandro, Miguel A. Rivera Ríos, y James Wilkie (coords.), 
Globalización y cambio tecnológico. México en el nuevo ciclo industrial mundial, México, UdeG, UNAM, UCLA-Program on Mexico y Juan Pablos Editor, 2006.

y René Caballero Hernández, "Cambio tecnológico y reproducción social. El perfil de una nueva teoría económica", en Economía Teoría y Practica, núm. 21. 2004.

Reinert, Erik S., How rich countries got rich and why poor countries stay poor, Nueva York, Carroll \& Graf, 2007.

, Competitiveness and its predecessorsa 500-year cross-national perspective, vol. 6, núm. 1, Amsterdam,Elsevier Science, 1995.

Reinhardt, Nola y Wilson Peres, "Latin America's New Economic Model: Micro responses and Economic Restructuring", en World development, vol. 28 núm. 9, Amsterdam, Elsevier Science, 2000.

Roitter S, Erbes A, Yoguel G, Delfini M. y Pujol A., Conocimiento, organización del trabajo y empleo en agentes pertenecientes a las tramas productivas automotriz $y$ siderúrgica, Buenos Aires, Electronic paper [http://pav-tramas.ungs.edu.ar/tramas/ Ungs/25_07_07/comparacion.pdf], 2008.

Rosenberg, Nathan, Dentro de la caja negra. Tecnología y economía, Barcelona, Llibres dels Quaderns, 1993.

Sábato, Jorge F., La clase dominante en la Argentina moderna: formación y características. Buenos Aires, CISEA, Grupo Editor, 1988.

Saviotti, Pier Paolo, "On the Dynamics of Generation and Utilization of Knowledge; the Local Character of Knowledge", en Structural Change and Economic Dynamics, vol. 18, núm. 4, Amsterdam, septiembre de 2007, pp. 387-408.

Schumpeter, Joseph, Capitalismo, socialismo y democracia, Madrid, Aguilar, 1968.

The Theory of Economic Development. Cambridge, Cambridge Harvard University, 1934.

Shanon, Benny, The Representational and the Presentational, Nueva York, Harvester, 1993.

Silverberg, Gerald, Giovanni Dosi y Luigi Orsenigo, "Innovation, Diversity and Diffusion. A Self-Organization Model", Economic Journal, vol. 98, núm. 393, Royal Economic Society, diciembre de 1988, pp. 1032-1054.

Stiglitz, Joseph, "Comments on 'Toward a Counter Revolution in Development Theory by P. Krugman", en Proceedings of the World Bank Annual Conference on Development 1997, Nueva York, Banco Mundial, 1992.

Stokes, D., Proceedings of the World Bank Annual Conference on Development, Washington, DC, Brookings Institution Press, 2003.

Teece, D. and Pisano, G., "The Dynamic Capabilities Firms: an Introduction", en Industrial and Corporate Change, vol. 3, núm. 3, Oxford, Oxford University Press, 1994, pp. I-I.

Volberda, Henk, Building the Flexible Firm, How to Remain Competitive, Oxford, Oxford University Press, 1998.

Wade, Robert, El mercado dirigido. La teoría económica y la función del gobierno en la industrialización del este de Asia, México, FCE, 1999.

World Bank, World Development Report. The Next Generation, Washington, DC, 2006. 